\title{
The role systematic lymphadenectomy plays in determining the survival outcome for advanced ovarian cancer patients: a meta- analysis
}

\author{
Dan Xu' ${ }^{1}$ Jinling Xue ${ }^{2}$, Rafi Rozan ${ }^{3}, \mathrm{Li} \mathrm{Li}^{4}$ \\ ${ }^{1}$ Department of Gynecology Oncology, Affiliated Tumor Hospital of Guangxi Medical University, Nanning 530021, China; ${ }^{2}$ Department of \\ Obstetrics and Gynecology, Yancheng No. 1 People's Hospital, Yancheng 224000, China; ${ }^{3}$ Department of Obstetrics and Gynecology, Georgetown \\ Public Hospital Corporation, Georgetown, Guyana; ${ }^{4}$ Department of Gynecology Oncology, Affiliated Tumor Hospital of Guangxi Medical \\ University, Nanning 530021, China \\ Contributions: (I) Conception and design: L Li, D Xu; (II) Administrative support: Guangxi Medical University Cancer Hospital; (III) Provision of \\ study materials or patients: L Li, J Xue, D Xu; (IV) Collection and assembly of data: D Xu, R Rozan; (V) Data analysis and interpretation: D Xu, L \\ Li, R Rozan; (VI) Manuscript writing: All authors; (VII) Final approval of manuscript: All authors. \\ Correspondence to: Li Li. Department of Gynecology Oncology, Affiliated Tumor Hospital of Guangxi Medical University, Nanning 530021, China. \\ Email: lili@gxmu.edu.cn.
}

\begin{abstract}
Background: This study aims to evaluate the role systematic lymphadenectomy (SL) plays in advanced ovarian cancer (OC) patients. A meta-analysis was done to compare the progression-free survival (PFS) rates and overall survival (OS) rates between SL and unsystematic lymphadenectomy (USL).

Methods: An extensive literature search from the dates of January 1, 1994, to today was performed. In total, we analyzed 15 studies [3 randomized controlled trials (RCTs) and 12 observation studies], which included 33,257 patients with advanced OC who underwent SL or USL. We compared the survival outcomes of PFS and OS between SL and USL stratified by research type, respectively. Pooled hazard ratios (HRs) and $95 \%$ confidence intervals (CIs) were combined and analyzed by using the Revman 5.3 software.

Results: For RCTs, SL did not improve the survival outcomes for advanced OC. Only 2 RCTs compared PFS, and 3 RCTs compared the OS rates between SL and USL. Two RCTs demonstrated that there was no difference in PFS between SL and USL (HR: 0.91; 95\% CI: 0.81-1.04; P=0.16>0.05); at the same time, 3 RCTs also demonstrated that there were no difference in OS between SL and USL (HR: 0.94, 95\% CI: 0.88-1.00; $\mathrm{P}=0.07>0.05$ ). However, in observational studies, SL showed increased PFS (HR: 0.93, 95\% CI: 0.92-0.95; $\mathrm{P}<0.00001)$ and OS (HR: 0.91, 95\% CI: 0.89-0.93, $\mathrm{P}<0.00001)$ for advanced OC patients. The heterogeneity and publication bias in the included studies were within acceptable thresholds.

Conclusions: These findings suggest the possibility that SL cannot improve survival outcomes for advanced OC patients. However, we cann ot completely ignore the results of observational studies. More relevant RCTs are needed to investigate the role of SL for advanced OC patients.
\end{abstract}

Keywords: Ovarian cancer (OC); systematic lymphadenectomy (SL)

Submitted Feb 10, 2020. Accepted for publication Mar 30, 2020.

doi: 10.21037/apm.2020.04.01

View this article at: http://dx.doi.org/10.21037/apm.2020.04.01

\section{Introduction}

According to a 2018 global report from the International Agency for Research on Cancer, the number of new cases of ovarian cancer (OC) was 295,144 , and the number of deaths was 184,799 (1). OC accounts for $2.5 \%$ of all malignancies and $5 \%$ of female cancer deaths due to its low survival rates, primarily driven by advanced-stage diagnoses (2). Because of a lack of typical early symptoms 
and the absence of practical measurements for early detection, more than $70 \%$ of patients, are newly diagnosed with advanced OC (3). Epithelial ovarian cancers (EOCs) are common in women of all racial groups, accounting for $90 \%$ of all OC cases. The mortality rate of EOC declined by $33 \%$ between 1976 and 2015 because of reductions in incidence and improvements in treatment (4).

Lymphatic spread is an important prognostic factor for EOC (5); however, the therapeutic role of systematic lymphadenectomy (SL) for advanced EOC is still controversial. The core issue of the controversy is whether an SL should be performed to stage or improve survival. "NCCN Guidelines Ovarian Cancer Version 1.2019" suggests that if macroscopically complete resection is possible, resection of clinically negative nodes is not required. Retrospective studies have shown that the rate of lymph node involvement in advanced EOC ranges between $48 \%$ and $75 \%$ (6). If we miss these involved lymph nodes, which are also resistant to chemotherapy, patients of advanced EOC will develop recurrent disease and eventually die.

The controversy between randomized controlled trials (RCTs) and retrospective studies raises has given rise to a number of meta-analyses on SL for OC in recent years (7-9). However, none of the meta-analyses arrived at definite conclusions. Since then, many new studies including 1 well-designed RCT have been conducted, but it is still necessary to reevaluate the effect of SL. Moreover, the above-mentioned meta-analyses (7-9) mostly focused on all-stage OC; however, most gynecology oncologists agree that the effect of SL is mainly on early stage EOC. The present meta-analysis was designed to compare the survival outcome of progression-free survival (PFS) and overall survival (OS) between SL and unsystematic lymphadenectomy (USL) in advanced EOC.

\section{Methods}

\section{Search strategy}

Possible eligible studies were searched for in the PubMed, Embase, and Cochrane Library databases by two independent reviewers. Bibliographies of relevant studies were also scanned by us to identify additional studies. The literature search was limited to the period between January 1, 1994, and March 31, 2019. The following keywords were used for the search: "ovarian neoplasm", "ovarian cancer", "ovarian tumor", "ovarian carcinoma", "lymphadenectomy", "lymph node dissection", and "lymph node sampling". All terms were expanded to include all subcategories to identify all published studies that fit the selection criteria. Only studies published in English were included in this meta-analysis.

\section{Study selection}

Studies included had to meet all of the following criteria: (I) used an RCT or observation study design, (II) examined advanced EOC (stage II-IV) patients, and (III) compared survival outcome (PFS or OS) between SL and USL. Exclusion criteria were as follows: (I) other histological types; (II) patients undergoing other treatments like surgery or chemotherapy before SL which could influence the survival outcome; (III) a lack of comparison of survival outcome (PFS or OS).

\section{Data abstraction}

Two reviewers independently abstracted the following parameters for each eligible study: first author, year of publication, study design, clinical stage, number of patients, period of follow-up, definition of SL and USL, hazard ratio (HR), and 95\% confidence interval (CI) [upper limitation (UL), lower limitation (LL)] of PFS and OS. Any discrepancies between the two reviewers were discussed until consensus was reached, or the third reviewer served as a tiebreaker.

\section{Statistical analysis}

The aim of this meta-analysis was to compare the survival outcome between SL and USL. There were many studies that did not present the direct results of HRs and 95\% CIs. Among some approaches for resolving this problem, the method by Meng et al. (10) was used to extract survival data (HRs and 95\% CIs) from survival curves by using R software.

This meta-analysis was performed using Review Manager 5.3. Heterogeneity was assessed by using Higgins $\mathrm{I}^{2}$, which measures the percentage of the total variation across studies that is due to heterogeneity rather than chance (11). It usually ranges from $0 \%$ (no observed heterogeneity) to $100 \%$ (maximal heterogeneity). $\mathrm{I}^{2} \leq 50 \%$ indicates no heterogeneity when using the fixed-effects model. $\mathrm{I}^{2}>50 \%$ may indicate substantial heterogeneity when using a random-effects model. In this meta-analysis, we used the 


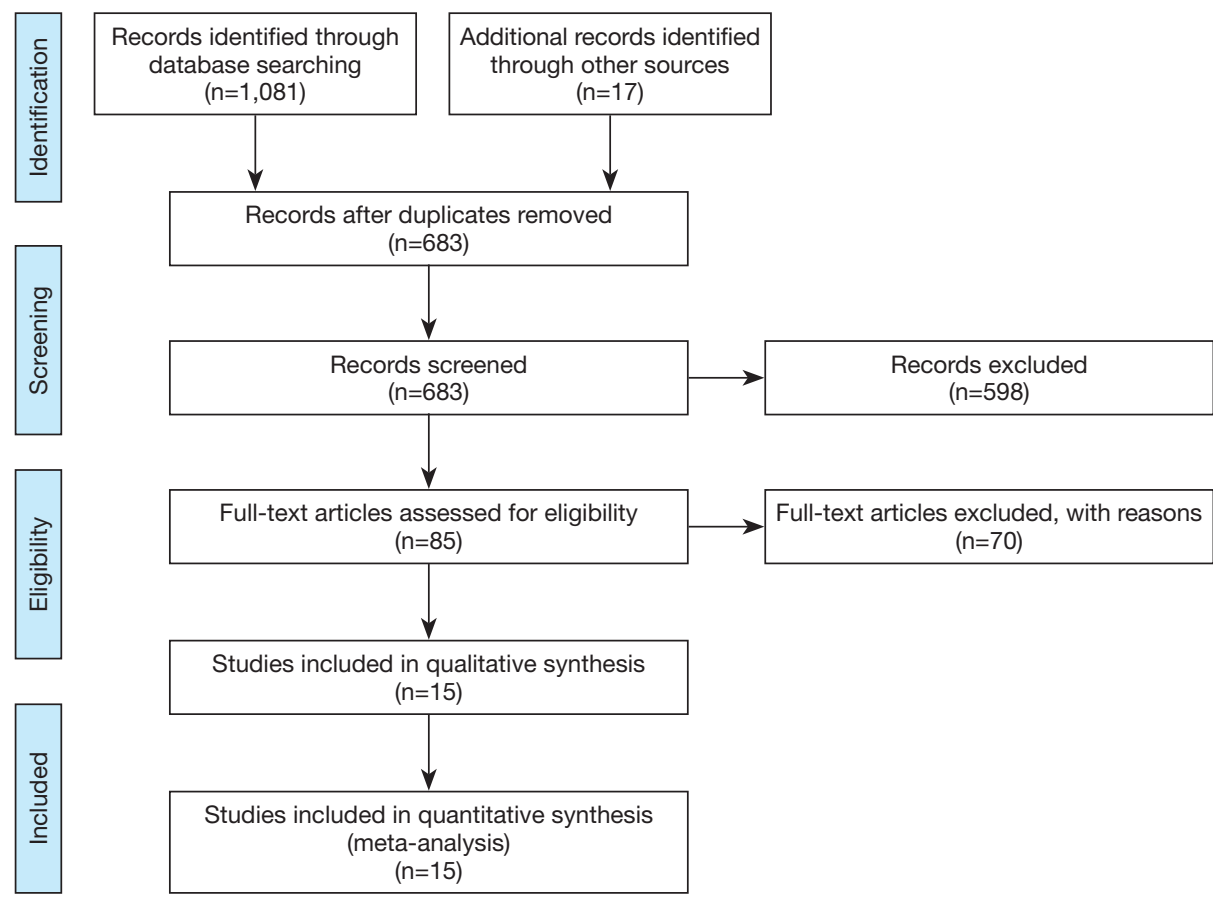

Figure 1 Flow diagram of the study selection process.

Table 1 Modified Jadad Assessments Scale for RCTs

\begin{tabular}{|c|c|c|c|c|c|}
\hline Included studies & Randomization (2') & Concealment of allocation (2') & Double-blinding (2') & Withdraws and drop-outs (1') & Score \\
\hline du Bois 2010 (14) & 1 & 1 & 1 & 1 & 4 \\
\hline Harter 2019 (15) & 2 & 2 & 2 & 1 & 7 \\
\hline
\end{tabular}

genetics inverse variance data type to combine Log HRs and SElogHRs, which were calculated by the following formula: SElogHR $=(\log U L-\operatorname{LogLL}) / 3.92 . \mathrm{P}<0.05$ was considered statistically significant.

\section{Results}

\section{Search results}

A total of 1,098 records were initially found based on the search criteria. After screening and exclusion, a total of 15 studies including 33,257 patients were eligible for this meta-analysis. A flow diagram of the study selection process is shown in Figure 1.

\section{Quality assessment}

For RCTs, we used a modified Jadad assessment scale (12), in which a study is judged according to four broad aspects: randomization, concealment of allocation, double-blinding and withdraws, and drop-outs. A full score is 7 , and a high-quality study is defined as $>4$ (see Table 1 ).

For observational studies, we used the NewcastleOttawa Assessment Scale (16), in which a study is judged according to three broad aspects: selection, comparability, and outcome. A full score is 9 , and a high-quality study is defined as score $>7$ (see Table 2).

\section{Study characteristics}

Of the literature included in this meta-analysis study, 3 studies were RCTs, and 12 studies were observational. Among the 12 observational studies, 3 studies were from the Surveillance, Epidemiology, and End Results (SEER) database. For this study, we divided patients into two 
Table 2 Newcastle-Ottawa Assessment Scale for observation studies

\begin{tabular}{|c|c|c|c|c|c|c|c|c|c|}
\hline Included studies & \multicolumn{4}{|c|}{ Selection } & \multicolumn{2}{|c|}{ Comparability } & \multicolumn{3}{|c|}{ Outcome } \\
\hline Kigawa 1994 (17) & is & is & is & is & is & is & 柁 & is & گ \\
\hline di $\operatorname{Re} 1996$ (18) & is & is & is & 弥 & 柁 & & 论 & & 级 \\
\hline Allen 1999 (19) & is & is & $i$ & is & 㧒 & 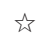 & 㧒 & 弥 & 放 \\
\hline Isonishi 2004 (21) & is & is & is & is & 岤 & is & is & & \\
\hline Aletti 2006 (22) & is & it & is & it & 计 & & it & 计 & ts \\
\hline Chan 2007 (23) & is & is & is & 为 & 放 & is & 访 & & \\
\hline Abe 2010 (24) & is & is & its & it & 岤 & & it & 论 & is \\
\hline Rungruang 2017 (27) & is & is & is & is & 泞 & & is & is & is \\
\hline Zhou 2018 (28) & 标 & 标 & is & 㑔 & 岤 & is & 㑔 & & \\
\hline
\end{tabular}

A: representative of SL; if truly representative of the average, 1 star was given. B: selection of USL; if they were from the same community as SL, 1 star was given. C: ascertainment of lymphadenectomy: if they had surgical records, 1 star was given. D: if there was no demonstration of outcome interest, 1 star was given. E: comparability of SL and unsystematic lymphadenectomy (USL) on the basis of some important factors including age, stage, chemotherapy; a maximum of 2 stars could be given. F: assessment of outcome; if the study was blind and independent, 1 star was given. G: if follow-up periods were longer than PFS or OS, 1 star was given. $\mathrm{H}$ : if there was an adequate number of SL subjects or no subject drop-out, 1 star was given. In the Newcastle-Ottawa Assessment Scale, studies with a score $>7$ were considered of good quality.

groups based on whether SL was performed or not. There were 7,829 patients in the SL group and 25,428 patients in the USL group. The definitions of SL and USL are shown in Table 3. Likewise, the detailed characteristics are also shown in Table 3.

\section{Survival outcome}

\section{Primary outcomes: PFS}

To investigate the role of SL in advanced OC on survival outcome, we conducted a meta-analysis using available information from 15 studies. Through considering some critical factors like selection bias, we separated RCTs and observational studies to compare the survival outcomes between SL and USL. There were two RCTs and three observational studies that conducted primary outcome (PFS) research. When we performed this meta-analysis according to the study design, no significant heterogeneities were detected (RCTs: $\mathrm{I}^{2}=26 \%$; observational studies: $\mathrm{I}^{2}=0 \%$ ), so the fixed-effects model was used. Two RCTs indicated that there was no difference in PFS between SL and USL (HR: 0.91; 95\% CI: 0.81-1.04; P>0.05; Figure 2). On the other hand, 3 observational studies showed that SL improved PFS (HR: 0.93; 95\% CI: 0.92-0.95; $\mathrm{P}<0.00001$; Figure 3).

\section{Secondary outcomes: OS}

Regarding the survival benefits, we also investigated the role of SL on OS. All 15 studies were conducted to compare the OS between SL and USL. Because of the different proof strengths between RCTs and observational studies, the analysis was performed based on the research type. A fixedeffects model was used due to there being no significant heterogeneities $\left(\mathrm{I}^{2}=0 \%\right.$ in RCTs, $\mathrm{I}^{2}=25 \%$ in observational studies). The overall pooled HR for RCTs ( 3 trials) was 0.94 (95\% CI: 0.88-1.00; P=0.07>0.05; Figure 4), indicating SL had no effect in improving the OS of advanced EOC. On the other hand, the pooled HR for observational studies (12 studies) was 0.91 (95\% CI: 0.89-0.93; $\mathrm{P}<0.00001$; Figure 5), showing SL was an important factor for improved OS in observational studies. 
Table 3 Clinical characteristics of 15 studies in the meta-analysis

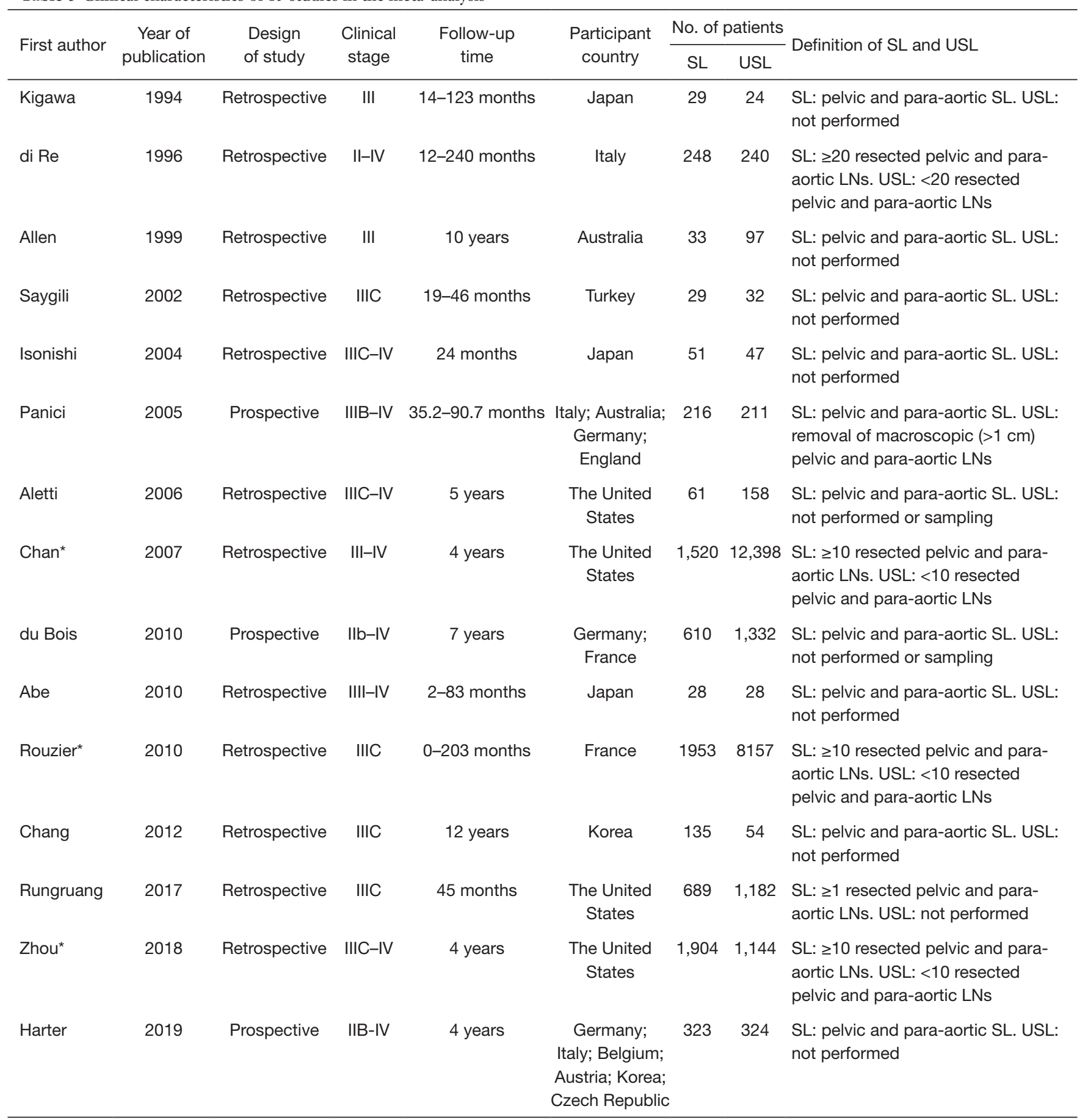

*, studies from Surveillance, Epidemiology and End Results (SEER). LNs, lymph nodes.

\section{Heterogeneity and publication bias}

Tests for heterogeneity demonstrated that there was no significant difference between study variation $\left(\mathrm{I}^{2}=0-26 \%\right)$. Also, the funnel plot for 15 studies in this meta-analysis revealed that all studies were distributed evenly across the graph, suggesting no publication bias in this meta-analysis (Figure 6). 


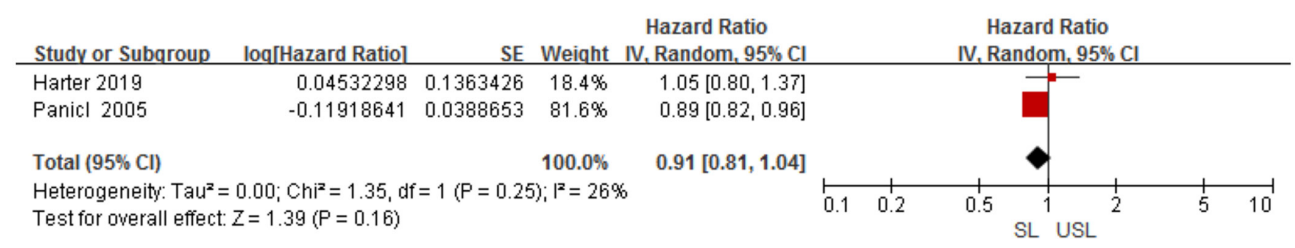

Figure 2 Comparison of PFS between SL and USL in two RCTs. PFS, progression-free survival; SL, systematic lymphadenectomy; USL, unsystematic lymphadenectomy; RCTs, randomized controlled trials.

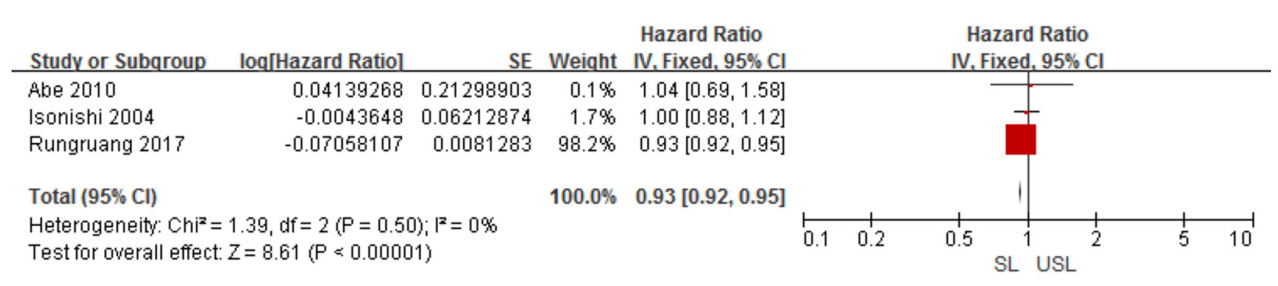

Figure 3 Comparison of PFS between SL and USL in three observation studies. PFS, progression-free survival; SL, systematic lymphadenectomy; USL, unsystematic lymphadenectomy; RCTs, randomized controlled trials.

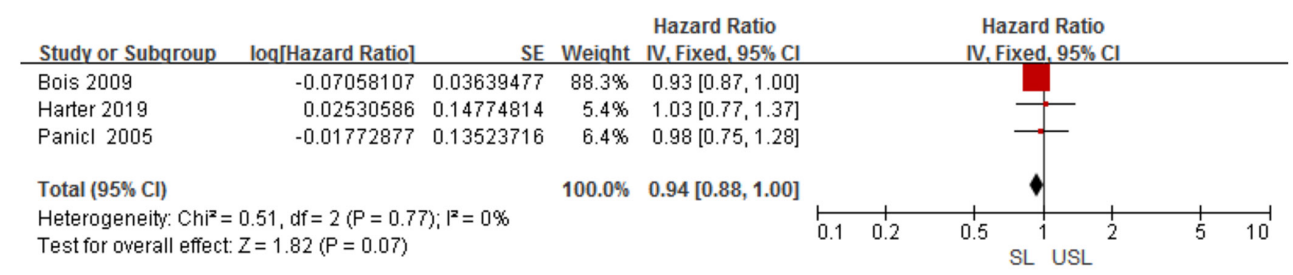

Figure 4 Comparison of OS between SL and USL in three RCTs. OS, overall survival; SL, systematic lymphadenectomy; USL, unsystematic lymphadenectomy; RCTs, randomized controlled trials.

\begin{tabular}{|c|c|c|c|c|c|c|c|c|c|c|}
\hline Study or Subqroup & loq[Hazard Ratio] & SE & Weight & $\begin{array}{l}\text { Hazard Ratio } \\
\text { IV. Fixed, } 95 \% \mathrm{Cl}\end{array}$ & & \multicolumn{3}{|c|}{$\begin{array}{c}\text { Hazard Ratio } \\
\text { IV, Fixed, } 95 \% \mathrm{Cl}\end{array}$} & & \\
\hline Abe 2010 & 0.08990511 & 0.17897695 & $0.5 \%$ & $1.09[0.77,1.55]$ & & & & & & \\
\hline Aletti 2006 & 0.2380461 & 0.37774071 & $0.1 \%$ & $1.27[0.61,2.66]$ & & & & & & \\
\hline Allen 1999 & -0.16749109 & 0.10798929 & $1.3 \%$ & $0.85[0.68,1.05]$ & & & $\longrightarrow$ & & & \\
\hline Chan 2007 & -0.16115091 & 0.0830421 & $2.2 \%$ & $0.85[0.72,1.00]$ & & & - & & & \\
\hline Chang 2012 & -0.22914799 & 0.12836944 & $0.9 \%$ & $0.80[0.62,1.02]$ & & & & & & \\
\hline Di Re 1996 & 0.17609126 & 0.40961284 & $0.1 \%$ & $1.19[0.53,2.66]$ & & & & & & \\
\hline Isonishi 2004 & -0.1739252 & 0.07523793 & $2.7 \%$ & $0.84[0.73,0.97]$ & & & - & & & \\
\hline Kigawa 1994 & 0.07918125 & 0.42583066 & $0.1 \%$ & $1.08[0.47,2.49]$ & & & & & & \\
\hline Rouzier 2010 & -0.16877031 & 0.03838727 & $10.4 \%$ & $0.84[0.78,0.91]$ & & & $=$ & & & \\
\hline Rungruang 2017 & -0.07058107 & 0.01414336 & $76.3 \%$ & $0.93[0.91,0.96]$ & & & & & & \\
\hline Saygili 2002 & 0.13033377 & 0.53371532 & $0.1 \%$ & $1.14[0.40,3.24]$ & & & 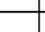 & & & \\
\hline Zhou 2018 & -0.17327748 & 0.05351885 & $5.3 \%$ & $0.84[0.76,0.93]$ & & & $\rightarrow$ & & & \\
\hline \multicolumn{3}{|l|}{ Total $(95 \% \mathrm{Cl})$} & $100.0 \%$ & $0.91[0.89,0.93]$ & & & 1 & & & \\
\hline \multicolumn{3}{|c|}{$\begin{array}{l}\text { Heterogeneity: } \mathrm{Ch}^{2}=14.67, \mathrm{df}=11(\mathrm{P}=0.20) ; \mathrm{I}^{\mathrm{z}}=25 \% \\
\text { Test for overall effect: } \mathrm{Z}=7.46(\mathrm{P}<0.00001)\end{array}$} & & & $\begin{array}{ll}\longmapsto & 1 \\
0.1 & 0.2\end{array}$ & 0 & $S L^{1}$ & 1 USL & 5 & 10 \\
\hline
\end{tabular}

Figure 5 Comparison of OS between SL and USL in all observation studies. OS, overall survival; SL, systematic lymphadenectomy; USL, unsystematic lymphadenectomy; RCTs, randomized controlled trials. 


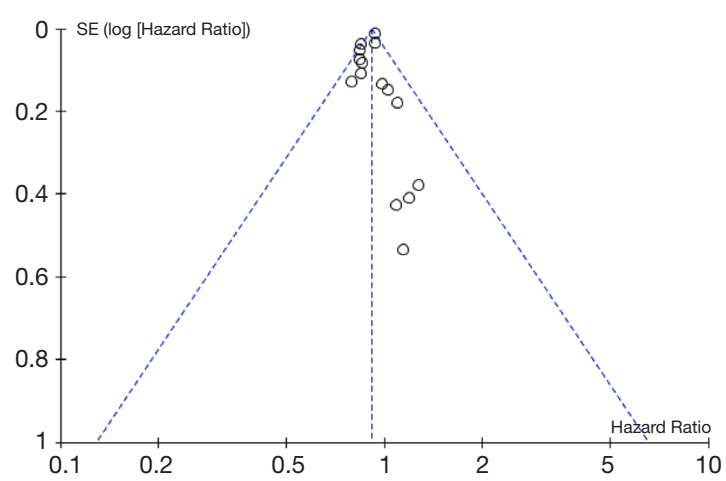

Figure 6 The funnel plot for 15 eligible studies in the metaanalysis.

\section{Discussion}

To clarify the effect of SL on survival outcome in advanced EOC, we performed this meta-analysis. After an extensive literature search, 3 RCTs and 12 observational studies were enrolled. Due to different research designs, we combined the RCTs and observational studies, respectively. PFS and OS are the most common survival outcomes for patient evaluation, which, in turn, represents the quality and quantity of life of women with advanced EOC. However, only 2 RCTs and 3 observational studies included in this meta-analysis published PFS results up. On the other hand, 15 included studies all reported the OS results of women with advanced EOC.

In our analysis, RCTs showed that SL may not improve PFS in advanced EOC, but three observational studies showed that SL can improve PFS compared with USL in advanced EOC. The discrepancy between RCTs and observational studies may be due to the different research designs: we believe the RCTs were well-designed, while the observational studies could not avoid selection bias. However, even among two RCTs, the conclusions differed. The former RCT reported that SL could improve PFS while the lymphadenectomy in ovarian neoplasm (LION) RCT reported the opposite result. However, the pooling of the meta-analysis indicated that SL cannot improve PFS. There are two explanations for this, as far as we can surmise. Firstly, the LION RCT was more precise and homogeneous. It amended some flaws in the former RCT like a more extended follow-up period. It added level 1 evidence to the long-standing research. Secondly, the greater number of cases in the LION RCT increased the weight of this RCT, and thus the combined result indicated that SL does not improve PFS in women with advanced EOC.
There are more studies focusing on the role of SL for OS in advanced EOC. A similar result has been documented for the secondary outcome-OS. Three RCTs showed that SL does not improve OS, while 12 observation studies showed that SL can improve OS. Unfortunately, but not surprisingly, we could not obtain a consensus conclusion as to whether SL improves the survival outcome in advanced EOC from this meta-analysis. There were only 3 included RCTs in which the number of patients involved was not large enough to describe the effect of survival outcome of SL in advanced EOC. Although 12 observational studies were included in this meta-analysis supporting the benefit of SL in women with advanced EOC, we think they are less convincing because of obvious selection bias and the deviation of weight by 3 large scale studies from SEER. In addition, most of the early observation studies compared OS of patients who underwent lymphadenectomy, which ranged from SL to node sampling with USL. These studies showed considerable differences in OS between groups. Hence, these studies were limited and did not account for the selection bias that SL has more favorable prognostic features than USL in advanced EOC.

It is well known that residual tumor size is particularly crucial to survival benefit (29). Lymph node metastasis rate was detected in $74.6 \%$ of advanced EOC patients (30). In our meta-analysis, 12 observational studies demonstrated the survival benefit of SL. Kigawa et al. (17) reported that omentum and retroperitoneal lymph nodes were the most frequent sites of metastasis. Similarly, Paik et al. (31) investigated recurrent EOC patients with no gross residual disease after primary debulking surgery and concluded that lymph nodes were at higher risk of recurrence. If these tumor cells were removed, further residual tumor burden could be reduced, which can affect survival outcomes. Keyver-Paik et al. (32) evaluated the lymph nodes of advanced OC undergoing neoadjuvant chemotherapy and reported that lymph node dissection even of unsuspicious nodes should be performed. However, the LION trial, which is a powered, international, multicenter trial, found that a macroscopically complete resection did not improve according to the increased radicality of the procedure. Thus far, there have been 3 well-designed RCTs for advanced EOC all stating the same conclusion: SL does not improve survival outcomes but results in treatment burden and harm in patients. Some meta-analyses (7-9) have been performed to study the role of SL. Gao et al. (7) and Zhou et al. (9) concluded that SL could improve OS in advanced EOC while Kim et al. (8) suspected the 
active role of SL in advanced EOC. These meta-analyses included all stage OC studies, while the role of SL in stage I OC has already been confirmed. However, there were previously not many prospectively randomized, powered, international, multicenter trials. Nowadays, we included 1 necessary LION trial in our meta-analysis to update and reevaluate the role of SL in advanced EOC. Our metaanalysis is the first to include $3 \mathrm{RCT}$ s to evaluate the role of SL in advanced OC. However, the controversy in the results between observational studies and LION raises several questions related to follow-up periods and the application of chemotherapy. In our meta-analysis, we included 15 studies which had OS and PFS results, but they rarely had data concerning side effects. Therefore, we did not analyze the side effects of SL, which is a limitation of our analysis. As a result, future randomized trials are needed to balance the risks and benefits of SL in advanced EOC (33). CARACO, an ongoing French trial (NCT0128490), scheduled to finish in 2022, is aimed at evaluating the impact of SL survival in patients with advanced EOC (34).

We look forward to this trial result to confirm the 3 RCTs result, so this issue can be conclusively resolved.

\section{Conclusions}

These findings suggest the possibility that SL cannot improve survival outcomes for advanced OC patients. However, we can not completely ignore the results of observational studies. More relevant RCTs are needed to investigate the role of SL for advanced OC patients.

\section{Acknowledgments}

Funding: This work was supported by the Scientific Research and Technological Development Plan of Guangxi Zhuang Autonomous Region (No. 1140003A-33).

\section{Footnote}

Conflicts of Interest: All authors have completed the ICMJE uniform disclosure form (available at http://dx.doi. org/10.21037/apm.2020.04.01). The authors have no conflicts of interest to declare.

Ethical Statement: The authors are accountable for all aspects of the work in ensuring that questions related to the accuracy or integrity of any part of the work are appropriately investigated and resolved.
Open Access Statement: This is an Open Access article distributed in accordance with the Creative Commons Attribution-NonCommercial-NoDerivs 4.0 International License (CC BY-NC-ND 4.0), which permits the noncommercial replication and distribution of the article with the strict proviso that no changes or edits are made and the original work is properly cited (including links to both the formal publication through the relevant DOI and the license). See: https://creativecommons.org/licenses/by-nc-nd/4.0/.

\section{References}

1. Bray F, Ferla J, Soerjomataram I, et al. Global Cancer Statistics 2018: GLOBOCAN Estimates of Incidence and Mortality Worldwide for 36 Cancers in 185 Countries. CA Cancer J Clin 2018;68:394-424.

2. Torre LA, Trabert B, DeSantis CE, et al. Ovarian Cancer Statistics, 2018. CA Cancer J Clin 2018;68:284-96.

3. Coleman RL, Monk BJ, Sood AK, et al. Latest research and treatment of advanced-stage epithelial ovarian cancer. Nat Rev Clin Oncol 2013;10:211-24.

4. Alvarez RD, Karlan BY, Strauss JF. Ovarian cancers: Evolving paradigms in research and care. Report from the Institute of Medicine. Gynecol Oncol 2016;141:413-5.

5. Ayhan A, Ozkan NT, Sari ME, et al. Impact of lymph node ratio on survival in stage III ovarian high-grade serous cancer: a Turkish Gynecol Oncol Group Study. J Gynecol Oncol 2018;29:e12.

6. Pereira A, Magrina JF, Rey V, et al. Pelvic and aortic lymph node metastasis in epithelial ovarian cancer. Gynecol Oncol 2007;105:604-8.

7. Gao J, Yang X, Zhang Y. Systematic lymphadenectomy in the treatment of epithelial ovarian cancer: a metaanalysis of multiple epidemiology studies. Jpn J Clin Oncol 2015;45:49-60.

8. Kim HS, Ju W, Jee BC, et al. Systematic lymphadenectomy for survival in epithelial ovarian cancer: a meta-analysis. Int J Gynecol Cancer 2010;20:520-8.

9. Zhou J, Shan G, Chen Y. The effect of lymphadenectomy on survival and recurrence in patients with ovarian cancer: a systematic review and meta-analysis. Jpn J Clin Oncol 2016;46:718-26.

10. Meng XY, Jin YH, Cheng XK, et al. Exacting data from survival curve and pooled survival curves by using $\mathrm{R}$ software. Chin J Evid Based Cardiovasc Med 2016;8:2-6.

11. Higgins JP, Thompson SG, Deeks JJ, et al. Measuring inconsistency in meta-analyses. BMJ 2003;327:557-60.

12. Oremus $M$, Wolfson C, Perrault A, et al. Interrater 
reliability of the modified Jadad quality scale for systematic reviews of Alzheimer's disease drug trials. Dement Geriatr Cogn Disord 2001;12:232-6.

13. Panici PB, Maggioni A, Hacker N, et al. Systematic aortic and pelvic lymphadenectomy versus resection bulky nodes only in optimally debulked advanced ovarian cancer: A randomized clinical trial. J Natl Cancer Inst 2005;97:560-6.

14. du Bois A, Reuss A, Harter P, et al. Potential role of lymphadenectomy in advanced ovarian cancer: A combined exploratory analysis of three prospectively randomized phase III multicenter trials. J Clin Oncol 2010:1733-9.

15. Harter P, Sehouli J, Lorusso D, et al. A randomized trial of lymphadenectomy in patients with advanced ovarian neoplasms. N Engl J Med 2019;380:822-32.

16. Cook DA, Reed DA. Appraising the quality of medical education research methods: the Medical Education Research Study Quality Instrument and the NewcastleOttawa Scale-Education. Acad Med 2015;90:1067-76.

17. Kigawa J, Minagawa Y, Itamochi H, et al. Retroperitoneal lymphadenectomy, including the para-aortic nodes in patients with stage III ovarian cancer. Am J Clin Oncol 1994;17:230-3.

18. di Re F, Baiocchi G, Fontanelli R, et al. Systematic pelvic and paraaortic lymphadenectomy for advanced ovarian cancer: prognostic significance of node metastases. Gynecol Oncol 1996;62:360-5.

19. Allen DG, Coulter J. Survival of patients with epithelial ovarian cancer and the effect of lymphadenectomy in those with stage 3 diseases. Aust N Z J Obstet Gynaecol 1999;39:420-4.

20. Saygili U, Guclu S, Uslu T, et al. Does systematic lymphadenectomy have a benefit on survival of suboptimally debulked patients with stage III ovarian carcinoma? A

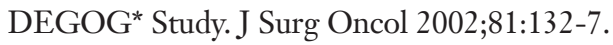

21. Isonishi S, Niimi S, Sasaki H, et al. Drug sensitivityrelated benefit of systematic lymphadenectomy during cytoreductive surgery in optimally debulked stages in IIIc and IV ovarian cancer. Gynecol Oncol 2004;93:647-52.

22. Aletti GD, Dowdy S, Karl C, et al. Role of lymphadenectomy in the management of grossly apparent advanced stage epithelial ovarian cancer. Am J Obstet Gynecol 2006;195:1862-8.

23. Chan JK, Urban R, Hu JM, et al. The potential therapeutic role of lymph node resection in epithelial ovarian cancer: a study of 13918 patients. Br J Cancer 2007;96:1817-22.

24. Abe A, Furumoto H, Irahara M, et al. The impact of systematic para-aortic and pelvic lymphadenectomy on survival in patients with optimally debulked ovarian cancer. J Obstet Gynaecol Res 2010;36:1023-1030.

25. Rouzier R, Bergzoll C, Brun JL, et al. The role of lymph node resection in ovarian cancer: analysis of the Surveillance, epidemiology, and end results (SEER) database. BJOG 2010;117:1451-8.

26. Chang SJ, Bristow RE, Ryu HS. Prognostic significance of systematic lymphadenectomy as part of primary debulking surgery in patients with advanced ovarian cancer. Gynecol Oncol 2012;126:381-6.

27. Rungruang BJ, Miller A, Krivak TC, et al. What is the role of retroperitoneal exploration in optimally debulked stage IIIC epithelial ovarian cancer? An NRG Oncology/ Gynecol Oncol Group Ancillary Data Study. Cancer 2017;123:985-93.

28. Zhou J, Zhang WW, Zhang QH, et al. The effect of lymphadenectomy in advanced ovarian cancer according to residual tumor status: A population-based study. Int J Surg 2018;52:11-5.

29. Polterauer S, Vergote I, Concin N, et al. Prognostic value of residual tumor size in patients with epithelial ovarian cancer FIGO stages IIA-IV: analysis of the OVCAD data. Int J Gynecol Cancer 2012;22:380-5.

30. Bachmann C, Bachmann R, Kraemer B, et al. Prevalence and distribution pattern of nodal metastases in advanced ovarian cancer. Mol Clin Oncol 2016;5:483-7.

31. Paik ES, Lee YY, Shim M, et al.Timing and patterns of recurrence in epithelial ovarian cancer patients with no gross residual disease after primary debulking surgery. Aust N Z J Obstet Gynaecol 2016;56:639-47.

32. Keyver-Paik MD, Arden JM, Lüders C, et al. Impact of chemotherapy on retroperitoneal lymph nodes in ovarian cancer. Anticancer Res 2016;36:1815-24.

33. Atallah D, Rassy EE, Chahine G. Is the LION strong enough? Future Oncol 2017;13:1835-7.

34. Classe JM, Cerato E, Boursier C, et al. Retroperitoneal lymphadenectomy and survival of patients treated for an advanced ovarian cancer: cARACO, a French randomized trial. J Gynecol Obstet Biol Reprod (Paris) 2011;40:201-4.

Cite this article as: $\mathrm{Xu} \mathrm{D,} \mathrm{Xue} \mathrm{J,} \mathrm{Rozan} \mathrm{R,} \mathrm{Li} \mathrm{L.} \mathrm{The} \mathrm{role}$ systematic lymphadenectomy plays in determining the survival outcome for advanced ovarian cancer patients: a metaanalysis. Ann Palliat Med 2020;9(3):912-920. doi: 10.21037/ apm.2020.04.01 